\title{
Communications
}

\section{Intelligent Arduino Home Based Security System Using Global System for Mobile Communication (GSM) and Passive Infrared (PIR) Sensor}

\author{
Ibrahim Goni $^{1}$, Rufai Hassan ${ }^{2}$ \\ ${ }^{1}$ Department of Computer Science Faculty of Science, Adamawa State University, Mubi, Nigeria \\ ${ }^{2}$ Department of Computer Engineering Faculty of Engineering, Federal Polytechnic, Bali, Nigeria
}

Email address:

algonis1414@gmail.com (I. Goni)

${ }^{*}$ Corresponding author

To cite this article:

Ibrahim Goni, Rufai Hassan. Intelligent Arduino Home Based Security System Using Global System for Mobile Communication (GSM) and Passive Infrared (PIR) Sensor. Communications. Vol. 7, No. 2, 2019, pp. 45-49. doi: 10.11648/j.com.20190702.13

Received: November 11, 2019; Accepted: December 2, 2019; Published: December 9, 2019

\begin{abstract}
With the advancement of technology things are becoming Simpler and easier in every aspect of life. Automation is the use of control systems and information technologies to reduce the need for human work. Security is an essential part of our life at this crucial moment, the problems of security in our home, industry, banks, schools, hotels and even offices cannot be tackle manually. The main aim of this research work is to design and implement an intelligent and reliable security system using Passive Infrared (PIR) and Global System for mobile communication (GSM) Module embedded on Arduino Uno board. $\mathrm{C}$ programme is uploaded on the board using Arduino IDE. The system have surveillance over the movement of people around the house premises $7 \mathrm{~m}$ to approach the door the security system send an SMS to a GSM phone (HTC) numbers included in the C programming codes.
\end{abstract}

Keywords: Arduino, Passive Infrared, GSM Module, Security, C Programming

\section{Introduction}

The advancement in control systems, nanotechnology, embedded programming, sensors and mobile computing, houses are also getting smarter more than ever before. Modern houses security is gradually converting from analog to digital form. Technology today has increased the safety and security of people and their belongings either at home, industry, schools, banks and even offices. Security is an essential part of our life. Many control systems have been designed to prevent access to unauthorized users into houses and facilities but the main reason for providing locks for our buildings [1]. Arduino is one of the tool for making computers that can sense and control more of the physical world than your desktop computer. It's an open-source physical computing platform based on a simple microcontroller board, and a development environment for writing software for the board [1].

In the research of [1] "Home automation referred to as "Intelligent home" or "automated home", indicates the automation of daily tasks with electrical devices used in homes. This could be the control of lights or more complex chores such as remote viewing of the house interiors for surveillance purposes". As designed and implemented in the research of $[2-5,11]$ Developed a wireless security system where an alarm system is programmed in form of graphical user interface (GUI). [12] Implement a security system against asset theft by using radio frequency identification technology. [13] Developed wireless home security system using GSM/GPRS. [14] Implemented a Microcontroller Based Security Door System (Using Mobile Phone \& Computer Set). [15] Online Home Security System. [16] Developed home automation using the PIC16F877A. [17] Developed an Internet Based Wireless Home Automation System for Multifunctional Devices. [18] developed a Bluetooth based Home Automation System using Cell Phone. [19] Designed and Implemented a Security Systems for Smart Home based using GSM technology. The main aim of this research work is to design and implement intelligent home based security system using GSM and PIR sensor. 


\section{Arduino UNO Board}

Arduino UNO is a board based on AT mega328 microcontroller. It consist of 14 digital input/output pins, six analogue inputs, a USB link for programming the onboard microcontroller, power jack, an ICSP header \& a reset button [6]. The software for Arduino works with many operating systems, such as Windows and Linux operating system. Therefore, the Arduino is better than many types of Microcontroller. The Arduino software language is based on $\mathrm{C}$ programming language. Arduino is an open source electronics prototyping platform based on flexible hardware and software. [7]. The Arduino software is supported by Windows, Macintosh OSX and Linux operating systems despite the fact that most microcontrollers are limited to Windows operating system. The software language is based on AVR $\mathrm{C}$ programming language and can be expanded through $\mathrm{C}++$ libraries. There are various types of Arduino microcontroller board available in the market including the Arduino kits and Arduino shields [8].

Uno" means "One" in Italian and is named to mark the upcoming release of Arduino 1.0. The Uno and version 1.0 will be the reference versions of Arduino, moving forward. The Uno is the latest in a series of USB Arduino boards, and the reference model for the Arduino platform; for a comparison with previous Versions [21]. The typical Arduino board is shown in the figure below.

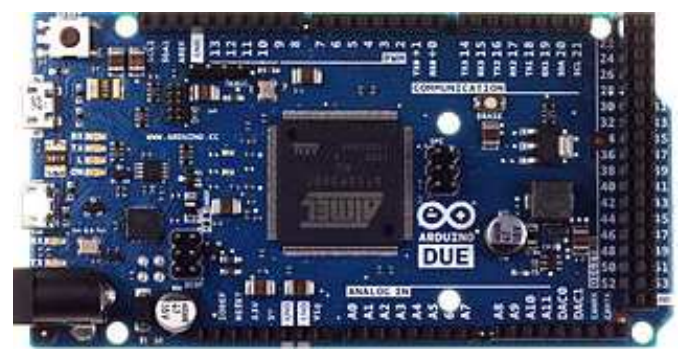

Figure 1. Arduino board [21].

\subsection{Passive Infrared Sensor}

Passive Infrared Sensor (PIR) It is a motion detector as this sensor performance is quite trustworthy $\&$ for a long time in security measures. They are small, low-cost, low-power, simple to use and don't wear out [9]. For that reason they are commonly found in appliances and gadgets used in Homes or businesses. They are typically referred as PIR, (Passive Infrared) Pyro electric, or IR motion sensors [10]. The figure below shows a typical PIR sensor.

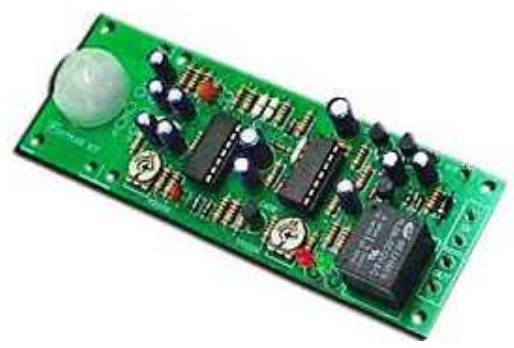

Figure 2. Passive infrared sensor [21].

\subsection{Power Unit of the System}

The power supply unit is the unit that energizes all other units of the system such as Arduino micro-controller, GSM module, and PIR sensor. The Battery is supplying 9V D. C voltage. In this design, $5 \mathrm{~V}$ and $4.3 \mathrm{~V} \mathrm{D}$. $\mathrm{C}$ voltage are required to power the system and LM7805 were used to prevent damage due to overheating. The LM340 and LM7805 Family monolithic 3-terminal positive voltage regulators employ internal current limiting, thermal shutdown and safe-area compensation, making them essentially indestructible. If adequate heat sinking is provided, they can deliver over 1.5-A output current. They are intended as fixed voltage regulators in a wide range of applications including local (on-card) regulation for elimination of noise and distribution problems associated with single-point regulation. In addition to use as fixed voltage regulators, these devices can be used with external components to obtain adjustable output voltages and currents. The figure below show a typical LM7805 regulator.

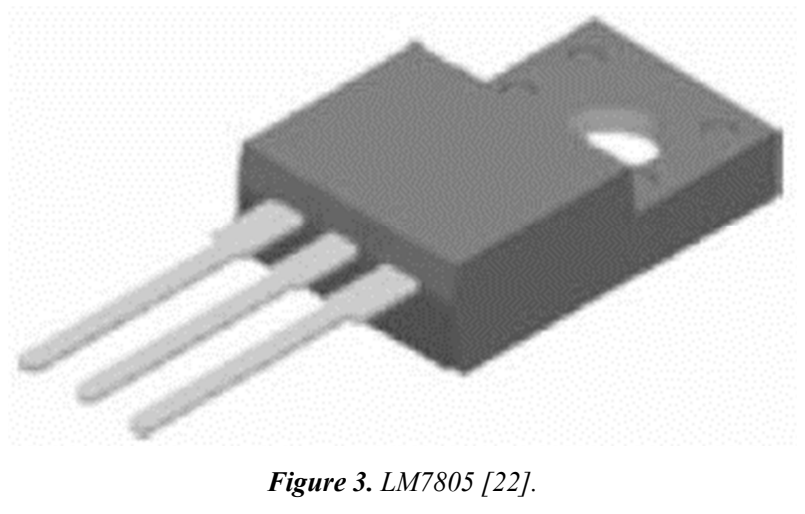

\section{Global System for Mobile Communication}

Global System for Mobile Communication (GSM) was first introduced in 1982 to develop a common European mobile communication. GSM is a globally accepted standard for digital cellar communications network. GSM is a circuitswitched system that divides each $200 \mathrm{kHz}$ channel into eight $25 \mathrm{kHz}$ time-slots. GSM operates on the mobile communication bands $900 \mathrm{MHz}$ and $1800 \mathrm{MHz}$ in most parts of the world. In the US, GSM operates in the bands $850 \mathrm{MHz}$ and $1900 \mathrm{MHz}$. It has an ability to carry $64 \mathrm{kbps}$ to $120 \mathrm{Mbps}$ of data rates The GSM network can be broadly divided into: The Mobile Station (MS), The Base Station Subsystem (BSS), The Network Switching Subsystem (NSS) and The Operation Support Subsystem (OSS). The currently available technologies for mobile data transfer are Circuit Switched Data (CSD), High Speed Circuit Switched Data (HSCSD), General Packet Radio Systems (GPRS), Third Generation (3G) Fourth Generation, Fifth Generation $5(\mathrm{G})$ and in some advanced countries Sixth generation (6G). GSM is composed of several functional entities, whose layout and interfaces are linked and perfectly defined GSM offers a number of 
services including voice communications, Short Message

Service (SMS), fax, voice mail, and other supplemental services such as call forwarding and caller ID. [20].

GPRS is also a service that provides actual packet radio access for mobile GSM and time-division multiple access (TDMA) users. The main benefits of GPRS are that it uses radio resources only when there is data to send and it also reduces dependence on traditional circuit-switched network elements. In addition, GPRS offers improved quality of data services in terms of reliability, response time, and features that are supported. The GPRS allows data rates of $115 \mathrm{Kbps}$, with a theoretical upper limit of $160 \mathrm{Kbps}$. Enhanced Data rate to GSM Evolution (EDGE), which is capable of offering data rates of $384 \mathrm{kbps}$ with a theoretical upper limit of 473.6 kbps, provides higher bandwidths. Because of this, EDGE is sometimes referred to as enhanced GPRS. Upcoming thirdgeneration $(3 \mathrm{G})$ wireless networks are poised to offer simultaneous voice, data, enhanced security and quality of service at peak downlink speeds of 2 to $14 \mathrm{Mbps}$ [23].

\section{Methods}

Circuit of this security system is configured as follows: Digital Pin number 2 of Arduino Mega2560 was directly connected to output pin of PIR sensor and $V_{\text {out }}$ and $G_{\text {nd }}$ pins of the buzzer were connected to the 13 and $G_{n d}$ pins of Arduino respectively, 10 and 11 pins of Arduino were directly connected to the TX and RX pins of GSM module respectively, It means a cross connection take place between Arduino and GSM module. Due to in-build Rs232 serial communication section on the GSM module, there is no need of RS232 serial communication section. Switch was connected to the power supply and also was connected to the $\mathrm{V}_{\mathrm{cc}}$ and $\mathrm{G}_{\mathrm{nd}}$ pins of Arduino respectively.

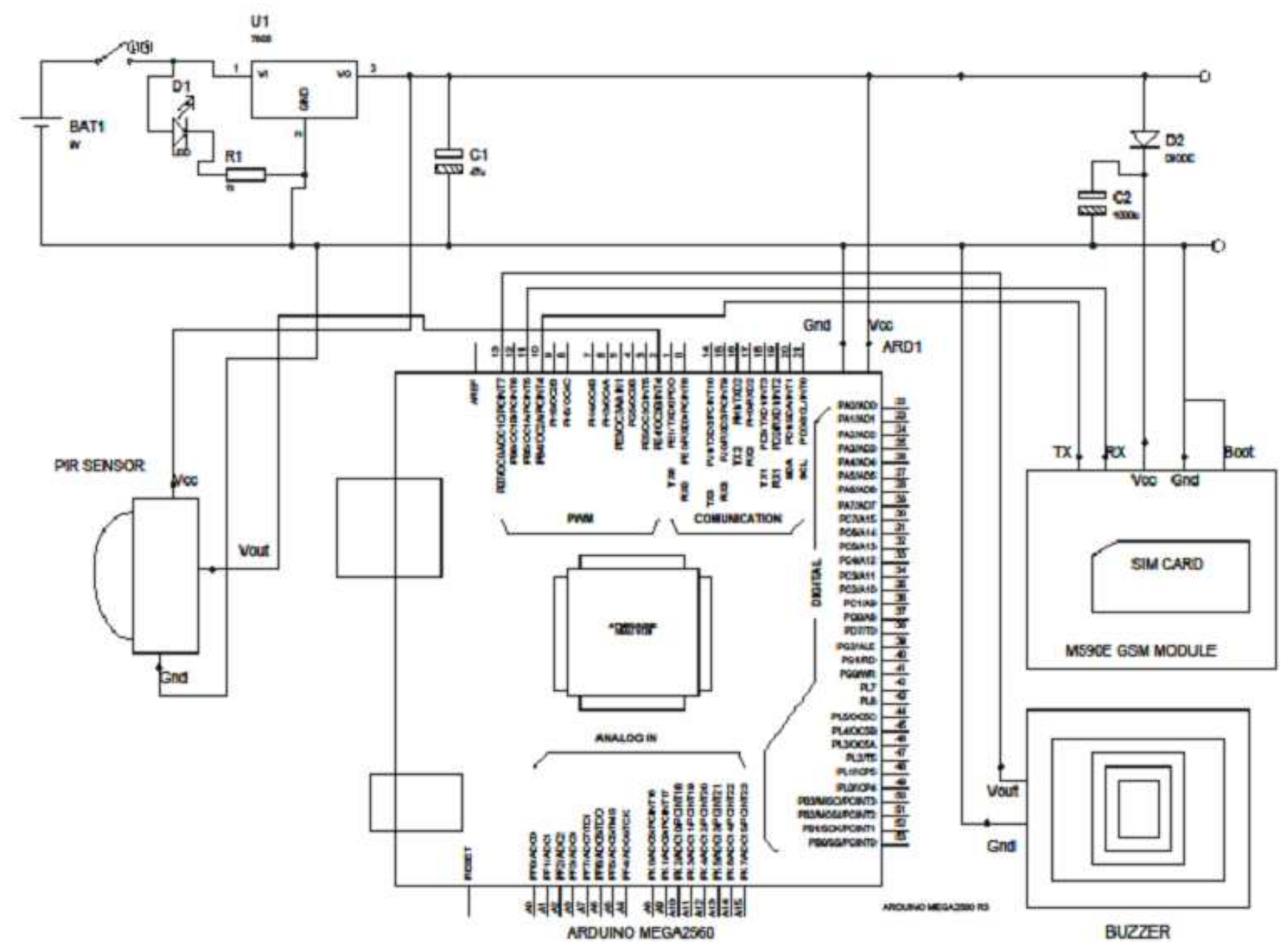

Figure 4. Circuit diagram.

The Arduino Home base security system was developed by implementing the sensor. In this research, only one sensor was used that is PIR sensor as a primary sensor for motion detection. The Arduino Home base security system triggered alarms to intrusion into the house through doors and windows as well as to the movement of a human being around the premises. The system kept surveillance over the movement of people and send SMS to a particular GSM phone numbers includes in the $\mathrm{C}$ programming codes that has been embedded on the Arduino. The whole system was the integration PIR sensor on Arduino MEGA2560 Board as shown below. 


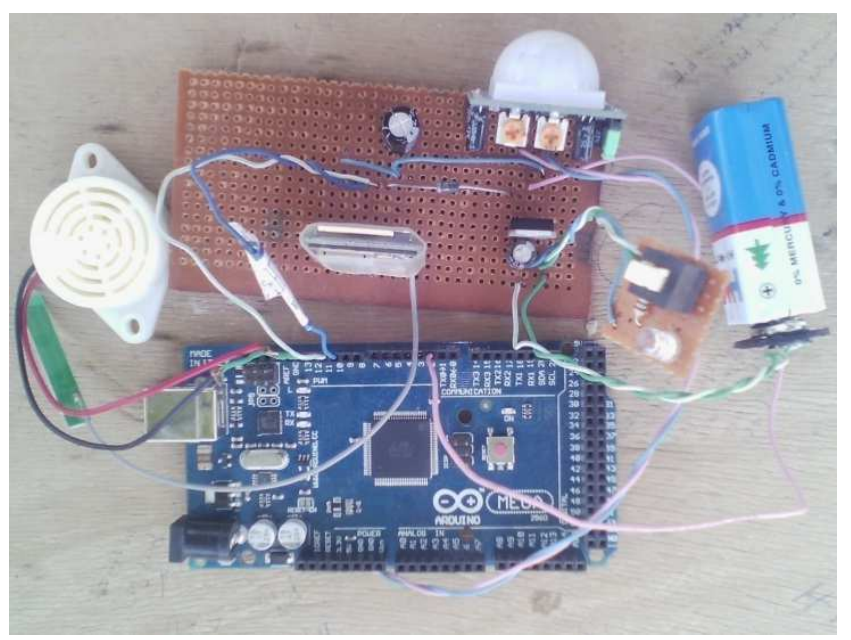

Figure 5. Arduino home-based security systems.

Figure 5 above shows the microcontroller unit, GSM/GPRS Module shield, PIR sensors, and buzzer.

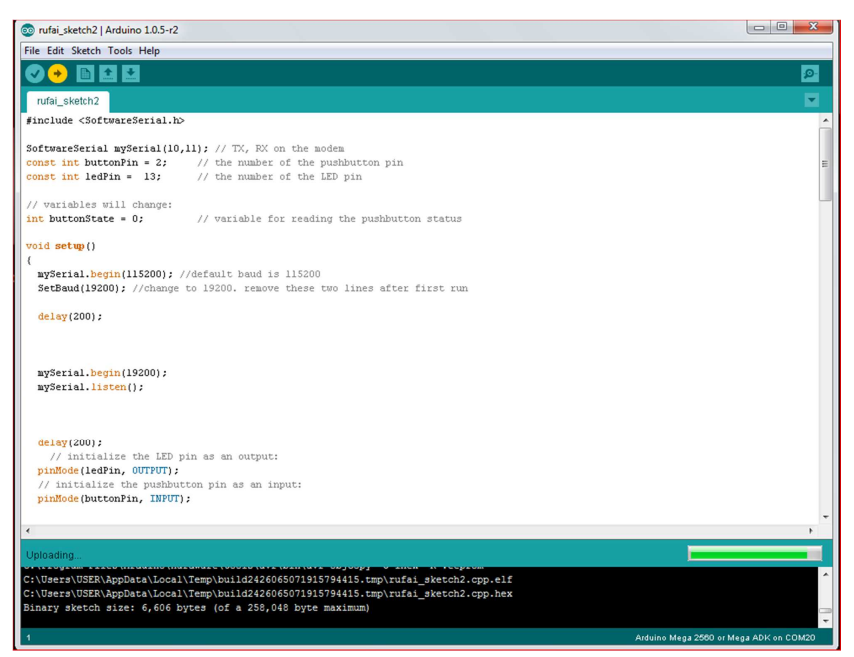

Figure 6. Screenshot of the Arduino Software IDE.

The Arduino integrated development environment (AIDE) is a cross-platform written in Java, whereas the programs are written in $\mathrm{C}$ or $\mathrm{C}++$ as shown in figure 6 above. The platform comes with a software library along with the code editor with features such as syntax highlighting, brace matching and automatic indentation.

The sensor along with the buzzer and the GPRS module are connected to the Arduino board and the application program which controls the microcontroller is written in Arduino IDE. The mobile station (or simply the mobile phone) interacts with the Arduino board with the help of the GPRS module connected to the board. The main function of the mobile station is to receive SMS from the microcontroller. The instructions and alerts are sent and received as an SMS message with the help of the GSM network available. There is no need for developing any new features in the mobile phone to use this system; any simple mobile phone supporting the SMS can be used as the mobile station in this application.

\section{Results and Discussion}

Home security is becoming necessary nowadays as the possibilities of intrusion are increasing day by day. The aim of this research work was to implement a home security system and the goal was achieved. The mobile station unit responds to the instructions sent by the GSM/GPRS Module according to the necessity of the application as well as triggers the alarm upon a critical situation. However the PIR sensor will trigger alarm if there is some movement around the restricted premises or if someone tries to intrude into the building through doors or windows. Figure 5 shows the message sent by the microcontroller to the mobile phone (HTC phone).

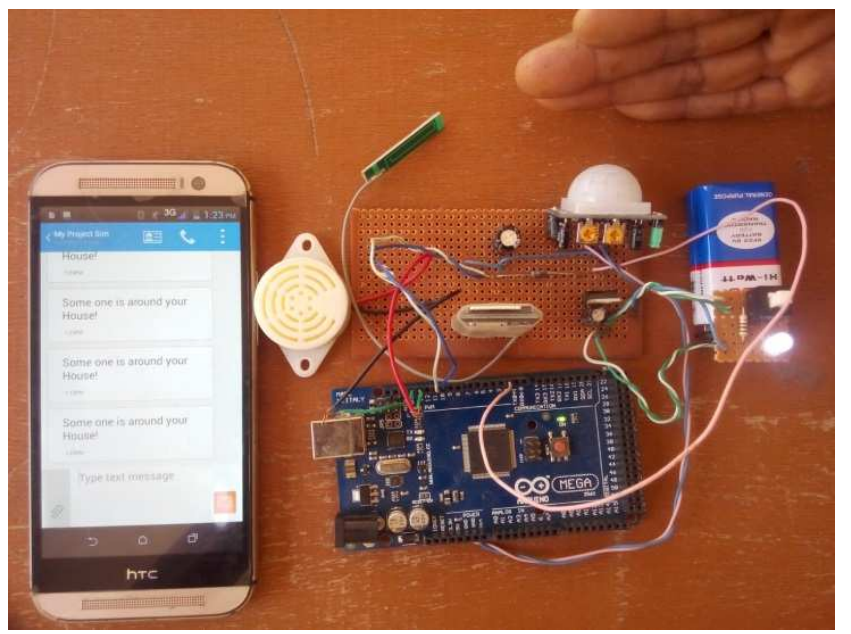

Figure 7. Show the whole system response and alarms received by the mobile phone.

\section{Conclusion}

With advancement of technology things are becoming Simpler and easier in every aspect of life. Automation is the use of control systems and information technologies to reduce the need for human work. Arduino and GSM Home Based Security System gives good response vigilant to the sensor and sends SMS when it identify an intruder. It is design and implemented. The research can be used as an effective security system when installed in a housing access point like doors, gates, windows etc.

\section{Recommendation}

Based on this research work the following recommendations were made.

The practical applications of this research will reveal its shortcomings. This small concept can be applied to some fields such as Smart Home System, Remote Sensing, Robotics, aeronautics, Home automation and banks, and many other related fields where continuous monitoring is needed.

Further research in this work would led to strong and reliable security system. 


\section{Acknowledgements}

It is my pleasure to acknowledge Adamawa state university Mubi by providing me with extensive training in research.

\section{References}

[1] Ali H. M. (2014) Arduino based home security system International Journal of Electronics, Electrical and Computational System IJEECS Vol. 3 (7) pp. 1-4.

[2] Jer-vui L., Yea Dat C. and Chin-Tin C. (2013) A Multilevel Home Security System International Journal of Smart Homes Vol. 7 (2) pp. 49-60.

[3] Tajika T., SaitoT. K. T., Oosaka N. and Isshiki M., (2003) Networked home appliance system using bluetooth technology integrating appliance control/monitoring with internet service, IEEE Transaction Consumer Electronics., vol. 49 ( 4) pp. 1043-1048.

[4] Jinaporn N., Wisadsud S., Nakonrat P. and Suriya A., (2008). Security System Against Asset Theft by using Radio Frequency Identification Technology Proceedings of ECTICON, pp. 761-764.

[5] Alkar A. Z., and Buhur U., (2005). An Internet Based Wireless Home Automation System for Multifunctional Devices, IEEE Transactions on Consumer Electronics, vol. 51 (4) pp. 11691174.

[6] Kaushal et al (2015) RFID based security and access Control system using Arduino with GSM module International Journal of Electrical \& Electronics Engineering Vol.2 (2) pp. $5-8$.

[7] Arduino Arduino board MEGA [Online]. Italy: Arduino available online at http://arduino.cc/en/Main/ArduinoBoard Accessed 17 July (2017).

[8] Subash Luitel (2013) Design and Implementation of a Smart Home System B. Sc. project Helsinki Metropolia University of Applied Sciences.

[9] Mustafijur R., Zadidul A. H. M. K., Sultanur N. Faisal K. and Golam M. (2015) Microcontroller Based Home Security and Load Controlling Using GSM Technology International Journal of Computer Network and Information Security Vol. 4 pp. 29-36.

[10] Omar T. A. (2014) Design and Implementation of Intelligent
Home Using GSM Network. M. Sc. dissertation Cankaya University.

[11] C. Wee K. S., N. K. Noordin, M. I. Saripan and R. Syamsul and A. R. Abdullah, "Theft Prevention using Wireless Security System (WSS) ", IEEE International RF and Microwave Conference,. 257-261.2008.

[12] N. Jinaporn, S. Wisadsud, P. Nakonrat and A. Suriya, "Security System against Asset Theft by using Radio Frequency Identification Technology", Proceedings of ECTICON, 761-764 2008.

[13] Y. Zhao and Z. Ye, "A Low Cost GSM/GPRS Based Wireless Home Security System", IEEE Transactions on Consumer Electronics, vol. 54, no. 2, (2008).

[14] P. Nwankwo, N. Ifeanyi and E C Joseph, "Design and Implementation of Microcontroller Based Security Door System (Using Mobile Phone \& Computer Set) " Automation and Control Engineering, Vol. 1 (1) 2013.

[15] P. Bangare S., A Pote, S L. Bangare, P Kurhekar and D Patil, "The Online Home Security System: Ways to Protect Home from Intruders \& Thefts", International Journal of Innovative Technology and Exploring Engineering Vol.2 (3) 2013.

[16] J. Burroughs, "X-10 home automation using the PIC16F877A," Lamp, vol. 10, article 10, 2010.

[17] A. Z. Alkar, and U. Buhur, "An Internet Based Wireless Home Automation System for Multifunctional Devices, "IEEE Transactions on Consumer Electronics, vol. 51, no.4, pp. 1169-1174, 2005.

[18] Piyare, R., Tazil M., "Bluetooth based Home Automation System using Cell Phone", IEEE 15th International Symposium on Consumer Electronics, pp.192-195, 2011.

[19] Jayashri Bangali and Arvind Shaligram" Design and Implementation of Security Systems for Smart Home based on GSM technology", International Journal of Smart Home Vol.7, No.6 (2013), pp.201-208.

[20] International Engineering consortium https://www.iec.org/

[21] https://components101.com/microcontrollers/arduino-uno

[22] http://www.taitroncomponents.com/catalog/Datasheet/LM780 5.pdf

[23] P. Rysavy, "Data Capabilities: GPRS to HSPDA", In: White Paper, Rysavy Research, 2005. 